\title{
MIDWIFING THE NOTION OF A ‘GOOD’ BIRTH: A PHILOSOPHICAL ANALYSIS
}

What makes a 'good' childbirth experience? It is about 'no one thing'. Most research focuses on a particular aspect of the experience, for to do otherwise is to go into a study with too big a question. Thus we turn our eyes to such aspects as 'care', 'place', 'relationship', 'attitudes', 'outcomes' and such like. Yet we know that each of those is somehow dependent on the other, each bringing a valuable perspective but few seeking to draw together a sense of the whole. Further, while we listen to stories from each participant, we reduce those accounts to themes, and then pluck snippets to show meaning. Once again we lose the whole.

\section{Methodological approach}

This hermeneutic paper, drawing on the writings of Heidegger [1889-1976] and Gadamer [19002002], knowingly dares to be different. We will turn mainly to philosophical writing to explore the emergent ideas for the purpose of thinking-together. Heeding that: "Thinking is not a means to gain knowledge. Thinking cuts furrows into the soil of Being" (Heidegger, 1959/1971, p. 70). We invite the reader to engage with us rather than to expect 'to be told'. Heidegger argues that 'method' has "pressed the sciences into its own services" (Heidegger, 1959/1971, p.74). Thus we have freed ourselves from some 'methods'. While it is convention to background a paper with recent research that links to the issue, we argue that would detract from the listening we seek to evoke. We have instead cleared a listening space. We draw on only one woman's story, simply letting the story speak to us. In the footsteps of Socrates we 'midwife' this story of birth (Fiumara, 1990).

The story came from one interview that was part of a research collaboration with Warkworth Birthing Centre. Primary Units in New Zealand have long been under political threat of closure (Donley, 1986). Our research (X et al. 2009; X et al. 2012; $X$ et al. 2014; $X$ et al, 2014) revealed that at this birthing centre $90 \%$ of women who initially booked to birth in this unit achieved a normal birth without intervention. Birth numbers from 2005-2008 averaged 163 per year, with an average of 51 primigravid women. The average transfer rate was 20 per year, $12 \%$. These figures continue to improve. In 2015 the normal birth rate was 92\%. Of 142 women admitted in labour, 132 achieved a normal birth at the birthing unit, and 5 at the destination to which they were transferred. In the period of our research women told us of the confidence they had in their ability to birth which transferred to their mothering experience. It was also important for them to birth within their own community; place mattered. 
Farry's (2015) recent New Zealand based research in which she compared low risk women who birthed at tertiary unit with those who birthed in a primary unit such as Warkworth found those in the tertiary unit were four times more likely to have an emergency caesarean section and significantly more likely to experience a PPH. At the tertiary unit their babies were three times as likely to have an Apgar below 7 at five minutes, and twice as likely to be admitted to the neonatal unit. . Davis et al (2010) mirrored these findings in an analysis of planned place of birth data of low risk births in New Zealand over the period of 2006-7, with 16,453 births meeting criteria. Of this sample, 2,877 women had birthed in primary units. Their findings revealed that for women who birthed in the tertiary units there was increased risk of assisted or operative modes of birth, increased interventions such as augmentation and episiotomy, and more likelihood that their baby would be admitted to a neonatal intensive care unit. They call for more research on the impact of the place of birth The Birth Place study in England (2011) confirms that for low risk women there is something about primary birthing units that facilities better outcomes than the bigger, technologically equipped, and medically staffed tertiary units.

Our research collaboration with Warkworth Birthing Centre began in 2008 with one study asking "what works well in this Centre?" The results were so inspiring that we went back in 2010 to continue the conversations. We used a hermeneutic approach with an appreciative lens, seeking to uncover meaning. Both studies were approved by the AUTEC Ethics Committee, with data returned to participants for approval soon after the interview.

From a total of forty seven interviews with women, midwives, nurses, and various other stakeholders there was a very consistent story that this was a place where' good' birth was the norm. As we listened to all those stories, there was one that seemed to capture a holistic sense of the many factors that came together to influence 'good'. It came from an interview, held, by the woman's choice, at the Birthing Centre, some weeks after she had given birth. It was recorded and transcribed. We followed the process as described by Caelli (2001) of removing extraneous material from the transcript, tidying the grammar and crafting the data into a style that privileged the story. Parts of this story were included in a conference presentation ( $X \& X, 2010)$. For this paper we have returned to the original transcript and gone through it once again asking: What matters in this story? What are the parts within the whole? What distracts? What tells the story of the things that come together to make a birth experience 'good'. The story offered in this paper is 500 words less than the original transcript. There was one section on how the woman felt mothered by the staff that has been trimmed back as it moved away from our focus on the constituents of 'good birth'. That 
portion of data has been analysed in a previous publication that focused on the postnatal experience $(x, 2012)$.

\section{Philosophical preparedness to listening}

Many years ago, as midwives we were drawn to a book chapter entitled 'Midwifery and philosophy' by Fiumara (1990). Socrates mother was a midwife. He too claimed himself a midwife, defining midwives as "persons capable of fostering the birth and life of thought" (1990, p. 147). To midwife thinking is to take leave, to stand aside, to make room for the thinking to emerge, to have "an 'attention' which only very skilled and authoritative midwives can teach us" (Fiumara, 1990, p. 145). It is a quest for the treasure that is "undescribed and indescribable" (p. 154). To listen attentively to the unsaid is to take on a commitment to thinking about what is "worthy of being asked" (p. 157); dwelling with the possible meanings, letting them ripen. It is to be attuned to our feelings and our moods for they reveal our understanding prior to language (Heidegger, 1927/1995). Listening requires our whole selves; "patience, irony, tenacity and assiduity" (p. 166). Fiumara reminds us that others may understand the insights we offer with greater insight than we ourselves. It is always a journey towards; never an arrival.

Both researchers and readers come to listen to a story with their own pre-understandings (Gadamer, 1982). Heidegger says "language is always ahead of us" (Heidegger, 1959/1971a, p. 75) in that we already have a way of talking about what is a 'good birth' and as such "remain entangled in a speaking that is persistently inadequate" (Heidegger, 1959/!971a, P.75). As authors we acknowledge the biases that infuse our listening. As our previous writings infer ( $X$ et al., 2009; $X$ et al., 2012; $X$ et al. 2014a: $X$ et alX et al, 2014b) we believe the Warkworth Birthing Centre offers a unique place in which women experience a safe birth they describe as 'very good' without on-site technical intervention. Further, we acknowledge our commitment to doing whatever we can to protect and preserve (Heidegger, 1993a) this space where normal birth remains the expected 'normal' outcome. We have our own backgrounds as midwives, our own learnings of how to attune to labour and birth, trusting a woman's remarkable ability to be at-one with her 'labouring' body, while ever watchful for signs of untoward stress that may point to a situation that becomes unsafe $(X, 2003,2010)$.

To listen afresh is to be attuned to that which is granted to us: "to think is before all else to listen, to let ourselves be told something and not to ask questions" (Heidegger, 1959/1971a, p. 76). Rather than speaking 'of' birth or even 'about' birth, we seek to let one woman's story of birth speak to us "from within" ( Heidegger, 1959/1971a, p.85) the saying. Our interest is not the object of knowledge 
but rather the "way making movement" (Heidegger, 1959/1971a, p.91). In opening ourselves we are touched, summoned, and in such a way sense our concern, our interest, our delight or despair. Thus the reading/listening is an attunement to feelings, to excitement, anxiety, head-nodding, or deep sighing. At the end of such listening we may not yet have the language to 'say' but rather carry within us a knowing that there is something that needs to be said. It is to begin by acknowledging that "we have not yet properly reached what concerns our being, not even approached it" (Heidegger, 1959/1971a, p.93).

To set us thinking, let us turn to Heidegger's (1977) question of what it means to dwell, to have that which matters preserved and cared for (Heidegger, 1993a). We seek to open such a space where 'what matters' about a 'good birth' shines forth and is understood with a deep sense of knowing. He suggests that conversations about such matters need an appreciation of the fourfold. He names the four as "earth and sky, divinities and mortals" (Heidegger, 1993a, p. 351). Each of the four mirrors the other three. That is the key argument of this paper. We cannot talk about the 'one' without at the same time, in the unspoken words on the page, also be talking about the other three. A woman is somewhere (earth) on a particular day (under the sky) giving birth (as mortal, with all the possibilities of life and death) attuned to the divinities (the sacred, mysterious, unnameable). Heidegger would argue "but we give no thought to the simple oneness of the four" (Heidegger, 1993a, p. 351) as we go about our everydayness. In other words, we tend to focus on the place of birth without at the very same time heeding the nature of the day or night, the particularities of the woman's obstetric history, her attunement (or not) to the joy of the experience (Crowther, Smythe, \& Spence, 2014). Heidegger argues that "safeguarding that dwells is fourfold" (Heidegger, 1993a, p. 351). . We interpret this to mean that a 'good birth' can only be experienced when there is a oneness of the four. What the 'four' consists of is nothing to be boxed, pinned down, or made simple. Rather, it is an opening of our minds to already be thinking of the other three; to always to mindful that a good birth is about 'everything'.

To help grasp the nature of the fourfold Heidegger offers the example of the spring that gives water watering the grapes that make the wine. The spring: "stays in the wine given by the fruit of the vine, the fruit in which the earth's nourishment and the sky's sun are betrothed to one another. In the gift of water, in the gift of wine, sky and earth dwell" (Heidegger, 1971b, p. 172). When we drink a glass of wine, the spring, grapes, sky and earth are far from our thoughts. Unless someone remarks "I wonder where these grapes were grown" we do not pause to consider the amount of rainfall in the region, the employment conditions of the grape pickers, the machinery required to get the juice we 
are drinking from grape to bottle. We simply drink the wine; yet 'everything' that brought us that mouthful lives on in the wine. Without the rain, without the back-breaking labour, without the bottling machine, there would be no wine from that bottle. Heidegger talks of how the gift of the wine gathers together the earth/sky/mortals/divinities. In such a way a woman coming into labour gathers to her the place where she will birth, the people who will be around her at that birth, the unfolding play of the day/night, and her own personal sense of what matters. All of these come together to become an experience that may or may not be 'good'.

\section{Jane's ${ }^{1}$ story}

Our hermeneutic task is to listen to what this woman says (Gadamer, 1982) and to wonder (Heidegger, 1927/1962) what made her experience 'good'. It is to consider that it is a story about a woman in labour (mortal), rich in extra-ordinary emotions (divinities), within a community in a particular season of time (sky), with the people and place around her (earthed). When we first heard Jane's story we had no thought of the fourfold. We have returned to the story at intervals over the last five years, each time saying to ourselves there is something precious within this telling. An earlier conference presentation had begun to unpack notions of confidence and the importance of place, giving a strong message that primary birthing units needed to be safeguarded. It was a beginning but we sensed there was something more to be heard. The lead author hosts a regular Heidegger Reading Group for doctoral research students. It was in once again grappling with the notion of the fourfold that the idea came to listen for the mortal, the divinities, the sky and the earth within this story. Thus we began to listen at a deeper level. The fourfold is complex, thus we weave our sense of how it fits into the telling of the story.

This was my second baby, the first in New Zealand. With my first baby I had a lot of medical intervention. He was induced; I had an epidural and I tore really badly with a third degree laceration. The doctor walked in the last two minutes of birth; that's all I saw of her.

Jane's mortality is revealed. Giving birth impacts self in a profound manner.

I was almost terrified about having a baby naturally again. I had considered getting a Csection. My midwife really worked with me. She never said that was a silly thing, you know you should have it natural. But she also wanted to give me the confidence that the choice was really there to have it either way. And I was really thankful for that the whole entire time, because ultimately I did want to have a vaginal birth.

\footnotetext{
${ }^{1}$ Pseudonym
} 
Jane was 'earthed' by the presence of a midwife who gave her confidence.

My peers were going through this fine, they were having their babies here and everything was turning out well. l even asked "does it hurt" which is the silliest question ever isn't it? This one friend of mine, all of them had their babies here at the Warkworth birthing centre she's like, "I've got three words for you 'ring of fire'"! But you feel the pain and it goes. That's the remarkable thing about birth is you feel it and then it dissipates rather quickly.

The 'earthing' continues with the discourse of her friends.

I have one very close friend who wanted a natural birth. But the midwife from here had to say "I'm sorry you're going to have to have a c-section". And that was important as well because the midwife knew when to make the decision to take the baby down to the hospital. They knew when medical intervention was necessary.

The earth feels safer, her own mortal-self less threatened by a story of safe-keeping.[Where I come from] people have babies at hospitals, so it was very hard to give that up, very, very hard. But it was really weird; the night that I went into labour, we were driving to the birthing centre and I just knew that I could have my baby here and it was going to be fine. And I think that decision doesn't just come up like that I think it was just all the coaching, just the gentle guidance by my midwife the entire time.

In labour, driving through the night, the divinities came with a clear sense of 'knowing'.

The choices were always there for me. I'm so glad I made the decision to stay here because it turned out to be just this amazing experience that will be with me forever.

Under the sky of that moment, Jane made a decision that led to something amazing.

When I had gone into labour and we were driving over to the Birthing Centre something came to me. They say you have a $6^{\text {th }}$ sense when you're in labour and I believe I did, that I was going to have my baby here and everything was going to be okay and I just knew it.

The divinities, the $6^{\text {th }}$ sense, gave Jane the confidence she needed to make a very big decision.

And driving 15 minutes here having contractions in a car with the seatbelt on, I knew I wasn't going to drive any further. My midwife had told us to meet here and she assessed me. She kind of looks up from after the exam and goes "we're not going to make it to a hospital." I said okay fine, let's have it here. 
The moral Jane, earthed by the reassuring presence of her midwife, under the sky of that particular night, guided by the divinities, chooses not to drive on. She will birth in this place.

Here it really seemed like I was in control and control's a very important thing for me, because birth can seem like you're out of control. Even with the pain and the contractions it all felt like, it was me, I was doing it and not someone else. So that was important.

The sky (the bigger context) is always out of our control, the divinities way beyond, but within this moment Jane felt earthed by her midwife, safe in her mortal self, encouraged by the divinities and at one with the space she found herself within. All of this gave her a sense of control in that she was doing this, she was the one in labour, and everything around her felt like it was in support.

And then my midwife: I don't know how you all do it but, her voice was just so melodic and so soothing. I think my husband tried it but couldn't quite get it right I'm like shh, shh let the midwife talk. I could be in the middle of a contraction and just the way she spoke to me, made me feel good. It made me feel like what I was doing was right and was going down the right path.

The melodic soothing of the midwife's voice held the grounding, held the trust, upheld the whisper of the divinities that all would be well.

And all she was saying was "well done, well done, you're doing well". It was the calmness and the confidence in her voice. I'll just remember that because it just made me think, I'm doing this and I'm doing this correctly

The mortal self is reassured by a deep knowing that she is doing this correctly. She is earthed, has a sense of control, and has a deep trust; one senses a giving-over of self to the labour, going with the experience in a anticipatory acceptance.

In between contractions, when I'm in the birthing pool, I asked her, "so how will you know this baby's coming?" She's like "oh I'll know, I'll know by the way that you're breathing, I'll just know your posture" and everything. I was like "okay". And sure enough I knew when the baby was coming, there was that moment I have to say, it just feels like your hips are literally cracking open

Jane was reassured that the midwife would know when the baby was ready to come. Then she found that she knew for herself. Her mortal self knew. 
There was that intense moment... I just stayed in the moment, and the baby came out. I could feel her head and I could feel her poke her shoulder out and then the other shoulder and then the whole baby came out. So there was a tense moment where it hurt; maybe I could have had a little bit of fear, but I think I had more, more determination than fear, more grace.

Birth is a body experience; intense, dynamic, painful. Jane, in her earthed, grace-filled being, met it with determination. She knew she could do this.

He came out. And then for a second I was just in recovery. My husband said that the midwife just held him to the top and I don't really remember him gasping for air or anything.

It just seemed the most natural thing,

I turned;

she put him in my arms and it was just,

it was just so beautiful.

It was beautiful and there is no other word but it was just this really tranquil, surreal, beautiful moment, very beautiful.

I'll always remember it.

Just joy and relief, like, oh we did this. And it turned out okay.

The sacredness of the moment of birth shines through when mortals, earth, sky and divinities gather.

At that point I trusted everything she was saying. My midwife could have told me that I should go for a couple of runs around the block and I would have been like okay that sounds good, yeah.

The earthing had proved itself. Jane's trust in her midwife was huge.

That night I couldn't sleep. I wanted to shout "joy to the world!" I heard someone in the kitchen. I walked down there. She saw me and was like "oh how are you?" I wanted to tell her everything that just happened to me and you know she listened and she's like "oh that's great". She got me something to drink and I just chatted with her. That's what I wanted, I wanted to talk to someone and she was great. I've forgotten her name but she just chatted with me and we talked and it was really nice. 
This was a huge experience in Jane's life; more than giving birth to a baby. It was about being caught up in the fourfold of life and celebrating all that it offered, all that it had revealed about her own self, all that was gifted in the sacredness of something amazingly special.

In that couple of days I was here, or just to call here when I have a problem, it's like you're being nourished, you're being taken care of, you feel like you've got someone to call I think that's how nourishment turns into strength. It's that you're able to replenish yourself. Birth does not end with the arrival of the baby. The mortal self is excited but exhausted. The midwife withdraws to rest. The sky changes. Yet still within the context there were others to nurture. Jane felt herself replenished by the earthing that continues.

Just going into the first couple of days just feeling, relaxed, replenished and nourished. I had three meals a day just given to me and I didn't have to wash dishes. It was just so nice, it was like a spa! I was able to go home and just feel relaxed and ready to kind of go on.

Jane holds together the fourfold in her sense of being cherished. She knows her wellbeing matters to others. She relaxes in her care of her baby. She leaves ready to go on.

All talk was positive. Everybody used a very positive speak. I look back on that, there was nothing negative. I can't think of any advice that was contradictory.

The sky has the potential to throw a 'look', a confusing piece of advice, something that undermines confidence. Somehow in this place the sky stays cloudless.

I know no one back where I come from that has had a natural birth with no drugs. So when I come here almost all my peers have had their babies here and have had good outcomes. And I think that speaks for itself. All the children are healthy happy children and the mothers talk about good experiences.

Jane recognises this is a place that upholds the capability of the mortal pregnant woman. There is proven trust that women can give birth naturally.

That gives me confidence. All these women, how was it and they're like "it was good". It was the most natural thing for them that yes you have it at the birthing centre and this is how you have your baby. They all got through it and they're all fine, absolutely fine. So I think that's what does it you know. 
The 'earth' in this community holds the ethos of normal birth. It is what happens here. The experience and outcomes are good. To love in this place is to be at one with the earth.

My husband went home and wrote this paragraph to his friends. It was like "I'm so proud of my wife. She gave birth the Kiwi ${ }^{2}$ way". It's funny he hadn't said it to me but he kind of posted it off to his friends which means even more. I hadn't known how the experience had affected him. That made me feel good that he was proud of me and all the decisions I had made about how we had our baby (Jane).

Jane recognises there were many decisions within her experience. She was guided by what was happening in her body, by the reassuring earthing of the midwife, by the positive supportive context of the sky within that place, and by the mysterious divinities. The fourfold gathered and held. Her Kiwi birth was about all of this; her own self, her midwife, the place of birth, the staff who held the culture and ethos of the place, and that which is often unspoken, a mysterious sense of knowing.

\section{The showing within Jane's story}

Saying means "to show, to let something appear, let it be seen and heard" (Heidegger, 1993b, p. 409) yet by the same token "What is spoken is never, in any language, what is said" (Heidegger, 1993b p.393).

There is something in this story that speaks to us of a manner of birth that is worthy of safeguarding. As we read the story over and over, more and more we come to appreciate the oneness of the four. To separate out the factors feels like doing violence to something sacred, yet the parts help us understand the whole (Gadamer, 1982). Let us return to the story to listen again.

This is the story of a woman who brought fear from her first highly technological birth to her second labour. Yet that fear was mitigated by the confident role modelling of her peers giving birth in this local birthing centre, by her midwife's trust that she would make wise decisions, and by a weird feeling, a $6^{\text {th }}$ sense of 'just knowing' that it was safe for her to birth in this low tech environment. Her own sense of mortality was at one with the place, the people, the night, and her own deep trust that all would be well. It was the oneness of the four that freed her to birth.

As labour progressed, in the pain of a contraction Jane was grounded to the earth by the soothing, melodic voice of the midwife, and embraced by the warm waters of the birthing pool. She was

\footnotetext{
${ }^{2}$ New Zealand is often referred to as 'Kiwi'
} 
drawn into her own knowing of when her baby was ready to be born; it was natural, of nature, a simple giving birth in the moment of readiness. There came a long, precious moment of beauty, tranquillity, surrealness, joy, and relief. It was everything at once: a coming together.

In the days that followed this new mother delighted in the joy of her new baby, of the amazing experience, of 'everything'. She drew others into her mood of joy. Her body was nourished. She had time to relax and recover. She was at one with earth, sky and divinities.

As she looks back on this 'good' experience, there is a sense that she believes all women should have the opportunity to birth in such a way. Yes, it is about 'place': a place embedded within a community where women encourage each other to have a natural birth because they themselves have had such positive experiences. Yes, it was about her midwife: one who gave her confidence of her very own, affirmed by the confidence of her friends. Yes, there were no risks that became problems within this birth. Neither were there interventions that disrupted the natural process.

This is a story of freeing birth "into a preserve of peace" (Heidegger, 1993a, p. 351). When everything is aligned, when the fourfold merges into the simple oneness and nature is free to be open to its ownmost ways, the essence of 'good birth' reveals itself.

The more we dwell with this story, wanting to use it towards the political ends of maintaining primary birthing units, wanting to showcase excellent midwifery, wanting to remind people of the magnificence of natural birth, the more we come to see that perhaps the fourfold is held together by something we will name as 'confidence'. There is something amidst our insights that is beyond pragmatic 'usefulness' in terms of technical tools. As we move on to grasp the notion that 'confidence' matters we are mindful that "we hear it only because we belong to it" (Heidegger, 1993b, p. 411), that we are being pointed to an unfolding way that lets things shine and also fade. Intriguingly the same 'pointing towards confidence' emerged as the overarching theme in another recent New Zealand study that explored women's decision making about place of birth (Grigg, Tracy, Schmied, Daellenbach, \& Kensington, 2015). The two experiences were side-by-side, one not influenced by the other.

\section{The pointing towards 'confidence'}

Confidence within place (the earth) 
In our listening and pondering we sense there is an underlying dynamic confidence that for the purpose of telling our story perhaps begins with 'place'. This community holds 'trust' in place. They serve the Trust Board that maintains the facilities and oversees the management of the Birthing Centre. More than that, they trust the Centre as the best place for their families (who have no reason otherwise) to experience birth. The community confidence that women can birth without intervention is fuelled by stories such as the one above. Without such confidence it is likely Jane may have made the effort to travel the extra hour to the tertiary hospital.

This particular community confidence was reignited in the 1990s when the government funded maternity unit was closed. The local people rallied to ensure there was a new alternative to enable women to birth 'in this place' close to family and friends. There had been a maternity hospital in this community since 1914. Such a place mattered (XXXX, 2009). 'They' already had confidence that with efficient transfer systems, a local birthing unit (without Caesarean Section or epidural anaesthesia) was their preferred option of maternity care. Generations of local women had already birthed in such a manner. They saw no reason for that to change. Their confidence was/is thus seasoned, tried and true.

In our listening to this story we are reminded of another voice from within the wider study, a member of the Trust Board:

I think it is pretty much a community place. People love coming up when they have got people they know who have had their babies here. Every woman that I know who has come through the birthing centre has a special kind of bond with it. I have got a girlfriend who lives across the hill and she overlooks it. She gets a special feeling to see the birthing room light come on and she knows someone is up there delivering. (Data collected 2010)

There is something about the light on the hill that 'speaks'. It gathers the fourfold of place, birthing woman, the wonder of a new life, on any particular night. Thus from various vantage points the community welcomes its new members. It becomes a story of more than 'confidence'. It shows how the outsider coming into this community has somehow come to sense that she too is welcome and safe to birth in this place. She too belongs. A 'good birth' is about having confidence in the place, yet when we talk of place there are the people, the mood, the mystery still to be embraced within our talking.

\section{Confidence within women (being mortal)}


In Jane's story we see how readily the confidence of one, two, three women becomes the confidence on which another grows her own. Jane's friend graphically described the intensity of the pain, but assured her about how quickly that pain goes. It was clear she was encouraging Jane to stay local, to believe she could birth without intervention. One can imagine Jane now telling her own story to a pregnant friend, who would not want such a birth! Perhaps we do not always recognise that it is 'other women' who shape what becomes the taken for granted assumptions of 'how birth will be' (XXX, 2010). Jane knew that 'where she came from' it would not have been possible for her to even consider such a birth. For a start she would have had no peer stories to give her the vision of how a natural birth could be so empowering, nor to infuse her with confidence that she too could birth in such a way. Stories are never about one thing. I went...she came...this happened...I felt...it was....and then... Context, people, mood, day, and the play between them are all open to interpretation as a story is told and heard. It is unlikely that women say to each other "I felt confident, you can too". Yet the other stories we have heard in two rounds of data collection related to this birthing centre (X, 2011; XXX., 2012; Smythe et al., 2009) showed us women who had birthed in this centre exuding confidence. We heed the words: "Depending on the quality of her matrescent, a woman may be greatly enlarged or diminished, for during this time, she is both vulnerable and powerful" (Thomas, 2001, p. 90). We believe Jane's speaks of an experience through which she was enlarged. Her story holds a timelessness within it; confidence is held, preserved and safeguarded, to be gifted again and again. A 'good birth' is about the woman having her own confidence, yet when we talk of the woman we are already thinking of where she is, under whose care, and within what rich possibilities of experience.

\section{Confidence within the midwife (coping with whatever is under the sky today)}

The midwife within Jane's story was clearly perceived as a rock, giving Jane confidence by respectfully answering her questions, freeing her to make her own decisions with no sense of being pressured. Alongside this the midwife seems to have been living out her own confidence in normal birth. Hearing of a friend being transferred to the tertiary hospital helped strengthen Jane's confidence that the midwife's practice was safe: she did not risk the wellbeing of mother or baby at the expense of striving for a normal birth. This midwife appears confident in her own practice judgements and skills. To work in such a birthing unit she needs to be confident in the ability of women's bodies to give birth naturally. Further, appreciating there are limited emergency facilities in this place, she would need confidence that she could manage any situation until transfer was swiftly enacted. Perhaps she too had a trust in the 'divinities', that an intuitive knowing would guide her attunement to any lurking risks. As a seasoned practitioner she would have lived through many 
experience of "thrownness" (Heidegger, 1927/1962) building her confidence that no matter the weather, no matter the time of day, no matter what else was happening within the unit or in her own personal life, there would be a safe way forward. Confidence 'is' but never as a static given (Smythe, 1998). For the midwife it is open to the play of possibilities of any given day. Our own midwifery experiences remind us that a nervous, anxious, stressful woman may equally undermine the midwife's own quiet confidence. Relationships merge into oneness of their own. When the midwife is confident, when the woman and her family are confident, when place, dynamic context, the unfolding labour, are all infused with a sense of calm, the oneness of the four again shelters and safeguards. A good birth is about the confident midwife, yet when we talk of the midwife we are already thinking of the confidence of the woman herself, within a place and community that exudes confidence, within a moment that feels 'right'.

\section{Confidence that 'is' (being open to the divinities)}

What is the nature of such calmness, such peace? Within the all-focusing experience of labour, Jane experienced a knowing that came from 'elsewhere'. She called it a $6^{\text {th }}$ sense. Others talk of "knowing, noughting, nothing, no thing, this coming to naught in which she found her greatest joy" (Lane, 1998/2007, p. 68). There is a confidence which comes (or not) beyond any rational explanation. It cannot be organised, planned or made, but the space for it to arise can be preserved and sheltered (X et al., 2014). "Non-rational or indeterminate and intuitively felt experiences at birth remain unexplainable yet paradoxically are perhaps the most meaningful and important" (XXX, 2015, p. 451). Such experiences are "an enigmatic mystery ... that transcends other limiting notions of time, place and culture." (XXX, 2015,p.455). Perhaps it is such transcendence that draws the fourfold into oneness. Perhaps transcendence loses its drawing power when aspects of the other three are found wanting. In other words, the peace-beyond-understanding that is the epitome of confidence is only free to emerge when the people, place, and unfolding situation come together in calm-full attunement. 'Everything' then becomes 'one'. Thus a good birth is about the deep confidence beyond understanding, yet when we talk of the mystery we are already thinking of the woman and her partner, her midwife, the place, the mood, the labouring, the moment. Even without 'wording' the fourfold the gathering gathers.

\section{Confidence as the oneness of the four}

We argue it is the oneness of the fourfold that creates the open space which frees women to give themselves over to experiences beyond anything they can control or imagine.

The philosopher, Rotenstreich (1972) unpacks his understanding of the nature of confidence: 
confidence may be related to a person, including oneself, and in this sense we speak of selfconfidence; or it may be related to another person, either in the singular or in the plural, or even perhaps to the course of events at large, to history, to the cosmos, to God (Rotenstreich, 1972, p. 348).

He talks about confidence as reliance, having trust in the people, place, situation: presupposing dependability and trustworthiness. Then he goes on to show how confidence binds all that one relies on together, and makes this telling statement: "Only the combination of the various aspects or strata of confidence gives a full picture of the phenomenon discussed" (Rotenstreich, 1972, p. 350).

The notion of the full picture brings us back to the oneness of the fourfold. When earth, sky, divinities and mortals (whatever they may represent) are all found trustworthy, when the woman comes to the approaching labour and birth depending on and trusting people, places and 'Gods' she knows as reliable, not only is confidence born and held, but in itself it reveals the essence underpinning being-confident. 'Goodness' is then revealed as the close neighbour of 'confidence'. Heidegger unpacks the notion of being a neighbour as "the two dwell face to face with each other, that the one has settled facing the other, has drawn into the other's nearness" (Heidegger, 1959/1971a, p. 82).

If confidence is as Rotenstreich (1972), suggests "the expectation that the promise will be fulfilled" (p.352) then our listening would tell us Jane emerged from her birth with fulfilment overflowing. Her confidence was flourishing; she had experienced a very good birth indeed. To talk of a 'good birth' is to gather together the woman, within place, surrounded by particular people, all embraced by mood. Confidence is within the gathering. Heidegger says "dwelling is always a staying with things"

\section{Discussion}

We have begun to grasp afresh the oneness of all that is involved in opening the space for a 'good birth'. This now exposes the challenge of how such insights may open the way for other women to have similar births. 
There is no quick fix recipe emerging from our thinking. There is however an imperative to first and foremost preserve, protect and safeguard 'places' where we know such birth is already happening. Those sanctuaries of birth are precious: not quickly replicated. Whatever trust has been built up, perhaps over generations, is fragile to the winds of change. To safeguard means to build shelter against inappropriate and unfounded undermining of trust. Further it is to be wary of opening the protective barrier to unnecessary technology which then sets its own agendas for how birth should be (Heidegger, 1977). The essence of natural birth needs the free space to unfold as nature dictates. The United Kingdom's NICE guidelines (NICE, 2014) are already leading the way in a quest to recreate sanctuaries of 'normal' birth in an understanding that 'place' is a key aspect of the fourfold. Based on the fact that birth outcomes for low risk women are the same when comparing obstetric units with midwifery led birthing units, the guidelines draw attention to the fact that the intervention rate is 'needlessly' higher in obstetric units. They recommend that low risk women should plan to birth in low-tech environments. We would suggest that in a more home-like setting relationships change the midwives have more time to focus on 'what matters'. The ambience is likely to be more peaceful, and the woman somehow feels different about her birth. Being-there, in a place which upholds all that is potentially 'good' about birth gathers together the fourfold, signalling and enacting a confidence in 'everything'. There is clearly something about a birthing unit closely integrated into the local community that makes it more than a building. It becomes a gathering place for all that promotes 'good' birth. Yet, even within the high-tech environment, the fourfold can still come together to shelter the things that matter..

We suggest the call is to ask questions of 'confidence' in the situations within which we are involved which are not always (or seldom) to be relied upon to offer women the experience of a 'good' birth. What in such a place, amidst the people, bound up in policies and guidelines, undermines confidence? Do the midwives and doctors who journey with women through their childbirth experience have embodied confidence in the process of natural birth? Are they attuned to watching and waiting with a calm, confident spirit? What, on any particular day or night, could unfold in such a way to threaten confidence? Could strategies be on standby to immediately remedy such situations? Do the people within 'this' community remember the stories of old when natural birth flourished? Are new stories of wonder-filled births being fed back into communities? Or does the media seize on any example of an unforeseen poor outcome to sow fear and terror into the very idea that someone could plan to birth outside of a tertiary hospital? Having said that, we would argue that it is very possible to hold the fourfold the yields a 'good' birth together even in the midst of a technologically 
equipped, medically staffed environment (XXX 2014). In the oneness of the four, disquiet in any dimension undermines confidence and thereby the possibilities of a 'good' birth. Fragmentation of the fourfold comes when one aspect is at odds with what feels 'right'. Yet, when the players are committed to holding confidence in women's abilities to birth without intervention (or even with what is minimally warranted), when they embody confidence in their own being, confidence itself perhaps becomes "the spiritual index finger" (Heidegger, 1993b, p. 410) which points the way to what is 'good'.

\section{Conclusion}

In midwifing this one woman's story have we listened intently enough? Have we heard the silence? Have we moved beyond filling the pages with words to 'say something' that matters? Have we given birth to something that can help us appreciate the oneness of the fourfold? More importantly, are we re-energised and recommitted to shelter and protect 'goodness' where, when and with whom we discern its budding possibilities?

Caelli, K. 2001., Engaging with phenomenology: Is it more of a challenge than it needs to be? Qualitative Health Research, 11, 273-281. doi:10.1177/104973201129118993

XXX. 2014., The joy at birth: An interpretive hermeneutic literature review. Midwifery, 30, 157-165. XXX., 2015. Kairos time at the moment of birth. Midwifery, 31, 451-457. doi:http://dx.doi.org/10.1016/j.midw.2014.11.005

Davis, D., Baddock, S., Pairman, S., Hunter, M., Benn, C., Wilson, D., Dixon, L., Herbison, P., 2011. Planned Place of Birth in New Zealand: Does it Affect Mode of Birth and Intervention Rates Among Low-Risk Women? Birth: Issues in Perinatal Care, 38, 111.

Donley, J., 1986. Save the midwife. New Women's Press, Auckland.

Farry, A., 2015. A retrospective cohort study to evaluate the effect of 'Place Presenting in Labour' and 'Model of Midwifery Care' on maternal and neonatal outcomes for the low risk women birthing in Counties Manukau District Health Board facilities 2011-2012, Unpublished thesis, Auckland University of Technology. http://aut.researchgateway.ac.nz/handle/10292/9467

Fiumara, G. C., 1990. Midwifery and philosophy. The other side of language: A philosophy of listening. Outledge, New York.

Gadamer, H. G., 1982. Truth and method (G. Barden \& J. Cumming, Trans.). Crossroad, New York.

Grigg, C. P., Tracy, S. K., Schmied, V., Daellenbach, R., Kensington, M., 2015. Women's birthplace decision-making, the role of confidence: Part of the Evaluating Maternity Units study, New Zealand. Midwifery, 31, 597-605. doi:http://dx.doi.org/10.1016/j.midw.2015.02.006

Gunn, J., Wilson, S., 2010. Strengthening midwives and families by delivering midwifery education to the regions concurrent session $11^{\text {th }}$ Biennial NZCOM National Midwifery Conference. Rotorua, New Zealand. September 2-4 2010 
Heidegger, M., 1927/1962. Being and Time (J. Macquarrie \& E. Robinson, Trans.). Blackwell Publishers Ltd, Oxford. (Original work published 1927)

Heidegger, M., 1971a. The nature of language. In P. Hertz (Ed.), On the way to language (pp. 57-108). HarperSanFrancisco, San Francisco. (Original work published 1959)

Heidegger, M., 1971b. Poetry, language, thought (A. Hofstadter, Trans.). Harper \& Row, New York. Heidegger, M., 1977. The question concerning technology and other essays (W. Lovitt, Trans.). Harper Torchbooks, New York.

Heidegger, M., 1993a. Building, Dwelling, Thinking. In D. Krell (Ed.), Basic Writings (pp. 343-365). HarperSanFrancisco, San Francisco.

Heidegger, M., 1993b. On the way to language. In D. Krell (Ed.), Basic Writings (pp. 393-426). San HarperSanFrancisco, Francisco.

Heidegger, M., 1995. Being and Time (J. McQuarrie \& E. Robinson, Trans.). Basil Blackwell, Oxford. (Original work published 1927)

Lane, B. 2007., The solace of fierce landscapes. Oxford, Oxford University Press. (Original work published 1998)

XXX. 2010., The rising rates of intervention in childbirth. British Journal of Midwifery, 17, 710-719.

NICE. 2014., Intrapartum care: care of health women and their babies during childbirth. United Kingdom: NICE. Retrieved from 190guidance.nice.org.uk/cg190

Rotenstreich, N., 1972. On Confidence. Philosophy, 47, 348-358. doi:doi:10.1017/S0031819100055960

$\mathrm{X}, 1998$. 'Being safe' in childbirth, A hermeneutic interpretation of the narratives of women and practitioners (PhD). Massey University, Auckland.

X., 2003. Uncovering the meaning of 'being safe' in practice. Contemporary Nurse, 14, 196-204.

X., 2010. Safety is an interpretive act: A hermeneutic analysis of care in childbirth. International Journal of Nursing Studies, 47, 1474-1482. doi:10.1016/j.ijnurstu.2010.05.003

XXXX., 2012. The dwelling space of postnatal care. Women and Birth. 26, 110-113, doi:10.1016/j.wombi.2012.05.001

XXXX., 2009. Warkworth birthing centre: exemplifying the future. New Zealand College of Midwives Journal, 41, 7-11.

XXXX., 2014a. Providing a safe space for birth in Warkworth, New Zealand. In R. C. White (Ed.), Global case studies in Maternal and Child Health (pp. 187-208). Jones \& Bartlett Learning, Burlington, MA.

XXXXX., 2014b. Revealing Tact Within Postnatal Care. Qualitative Health Research, 24, 163.Thomas, T., 2001. Becoming a mother: Matrescence as spiritual formation. Religious Education, 96, 88-105. doi:10.1080/003440801750367886 